\title{
Development of On-line Instrumentation and Techniques to Detect and Measure Particulates
}

\section{Quarterly Technical Progress Report}

From April 1, 2004 to June 30, 2004

Principle authors: Sheng Wu, Steve Palm, Yongchun Tang, William A.

Goddard III

Date Report was issued: July 31, 2004

DOE Award number: DE-FC26-02NT41581

Name and Address of Submitting Organization:

California Institute of Technology

1200 East California Blvd.,

Pasadena, CA91125 


\section{Disclaimer}

This report was prepared as an account of work sponsored by an agency of the United States Government. Neither the United States Government nor any agency thereof, nor any of their employees, makes any warranty, express or implied, or assumes any legal liability or responsibility for the accuracy, completeness, or usefulness of any information, apparatus, product, or process disclosed, or represents that its use would not infringe privately owned rights. Reference herein to any specific commercial products, process, or services by trade name, trademark, manufacturer, or otherwise does not necessarily constitute or imply its endorsement, recommendation, or favoring by the United States Government or any agency thereof. The views and opinions of authors expressed herein do not necessarily state or reflect those of the United States Government or any agency thereof.

\section{Abstract}

In this quarter, we have constructed the first field deployable PM measurement system. This system is retrofit from the system that we designed and tested in the lab, and by adding light blocking covers and rugged electronic boxes, we are now ready to test the instrument in our industrial collaborator's site with real engines. We have also collected tons of data on standard PM particles with our lab instrument. 


\section{Table of Content}

Development of On-line Instrumentation and Techniques to Detect and Measure Particulates ... 1

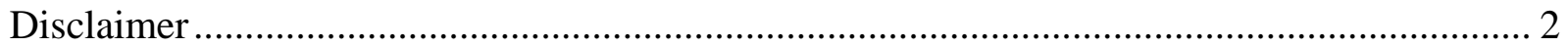

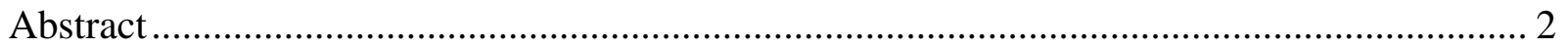

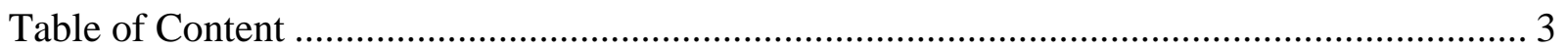

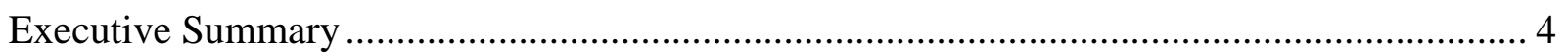

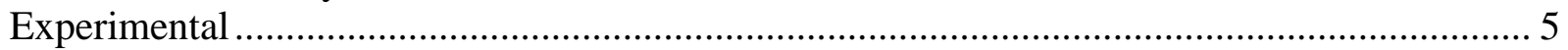

1. Basic hardware setup for field use ................................................................................ 5

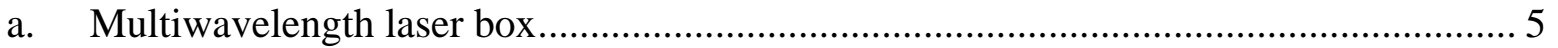

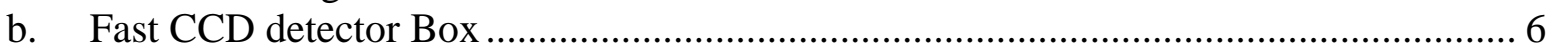

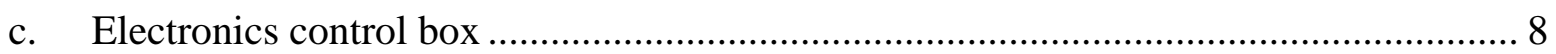

2. Results of light scattering microscopy ……………...................................................... 9

3. Computer program that simulates scattering with lasers of different wavelengths ...... 12

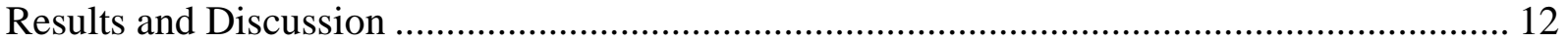

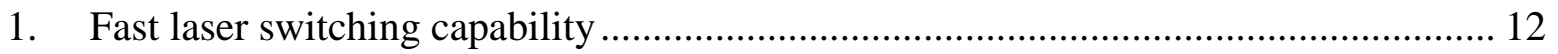

2. Microscopy application and single particulate analysis.................................................. 12

Work plan for the 8 the quarter of the project ........................................................................ 13

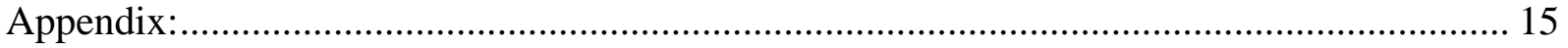




\section{Executive Summary}

During the $7^{\text {th }}$ quarter of this project, we are focusing on putting the gears together for the field test. The basic setup consists of 4 major blocks

1. The multiwavelength laser system

$>$ We are putting all the lasers into a box with each different laser launching sequentially, this is close to our test bed in the laboratory before, but we now have them all packaged

$>$ We also have designed and testing the interface to the control electronics block

2. The linear CCD wide-angular detection system

$>$ We have designed and are assembling the CCD system in a sealed box, with very careful control of strong stray light

$>$ We also have designed and are testing the interface to the control electronics block

3. The control electronics for the above 2 blocks

$>$ We have finished design and assembly of the first 2 prototype boxes and tested one of them

$>$ We have also included USB embedded system to the PC for this box

4. The computer interface to block \#3 and data analysis program

$>$ We have designed the PC host program to the box in block \#3

$>$ We are retrofitting the data analysis software that was designed for the laboratory experiment for the USB interface.

We also are pushing hard to prove the particulate analyzing capability of our microscope version of the multiwavelength laser scattering technique. We have observed synthesized nanometer $(80 \mathrm{~nm})$ particulates embedded inside cells, this is opening a new door to many great applications in microscopic world. 


\section{Experimental}

\section{Basic hardware setup for field use}

\section{a. Multiwavelength laser box}

In the multi-wavelength laser system, we will reuse the multiwavelength laser block that we build for the laboratory demonstration, but we added logic controls to this block so that we could firing the lasers sequentially through computer control. We have finished design and are putting together the system in a box.

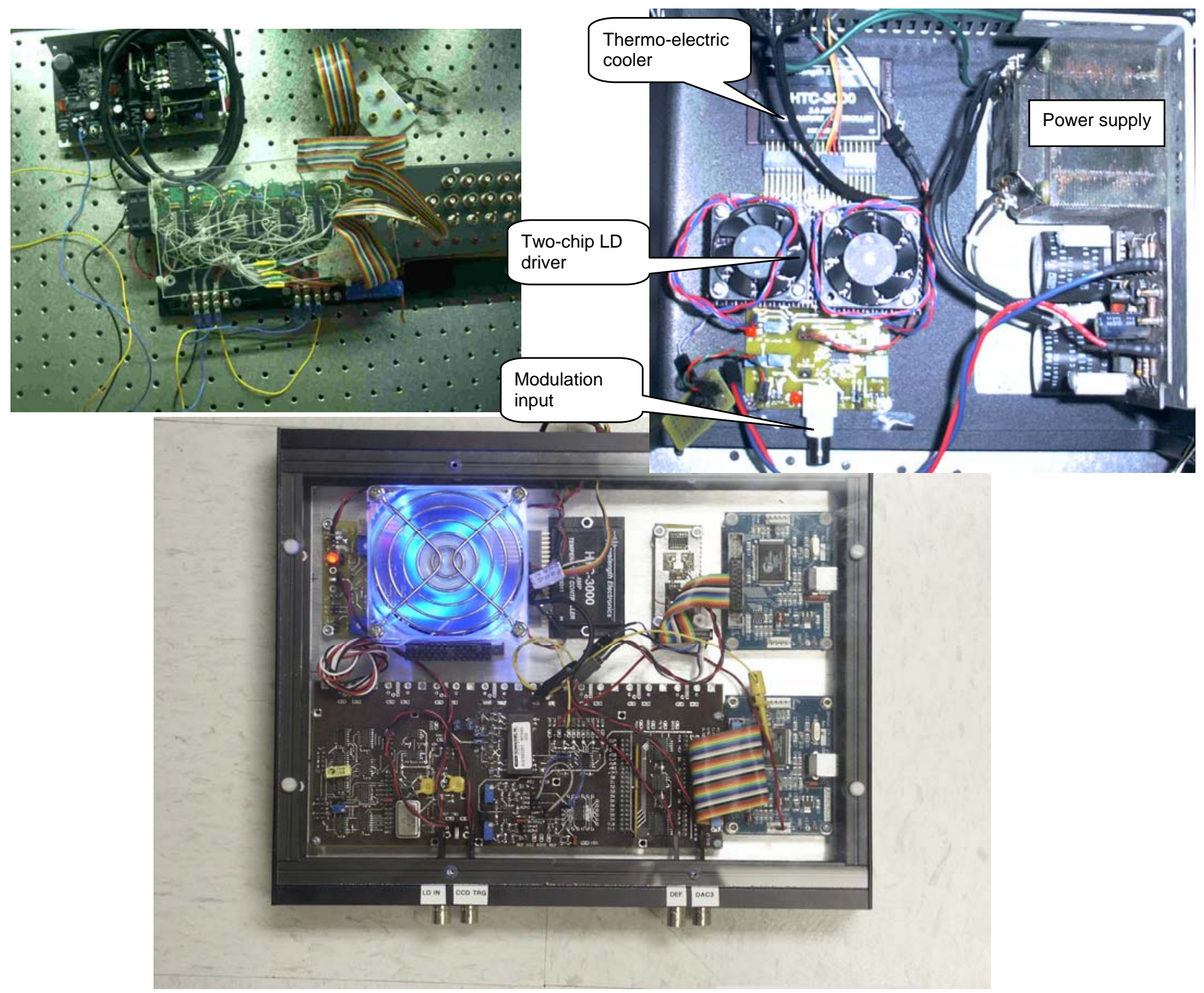

Figure 1. Picture of the LD driver board, TOP: For laboratory demonstration that we built before, left is the low power diode laser controller array (8 units), and right is DPSSL laser controller. BOTTOM: For field use, integrated CCD controller and lower power diode laser and DPSSL laser controller. 
Table 1 . The assembly uses 10 lasers at different wavelengths.

\begin{tabular}{|l|l|l|l|l|l|l|l|l|l|l|}
\hline Wavelength & $635 \mathrm{~nm}$ & $650 \mathrm{~nm}$ & $660 \mathrm{~nm}$ & $780 \mathrm{~nm}$ & $810 \mathrm{~nm}$ & $830 \mathrm{~nm}$ & $980 \mathrm{~nm}$ & $355 \mathrm{~nm}$ & $532 \mathrm{~nm}$ & $1064 \mathrm{~nm}$ \\
\hline Power (mW) & 30 & 40 & 30 & 80 & 200 & 30 & 30 & 14 & 30 & 200 \\
\hline Package & TO & Cir. TO & Cir. To & Bare & C-mnt & TO & FC & DP/PQS & DP/CW & DP/CW \\
\hline
\end{tabular}

\section{b. Fast CCD detector Box}

In the receiver box, we designed stray light blocking structures to filter out the ambient light and only detect light from the scattering area of interest.

We are putting the multi-wavelength lasers assembly and the fast CCD detector in two boxes, as pictured below, the detector or the laser launch box could be rotated around the sample area of interest.

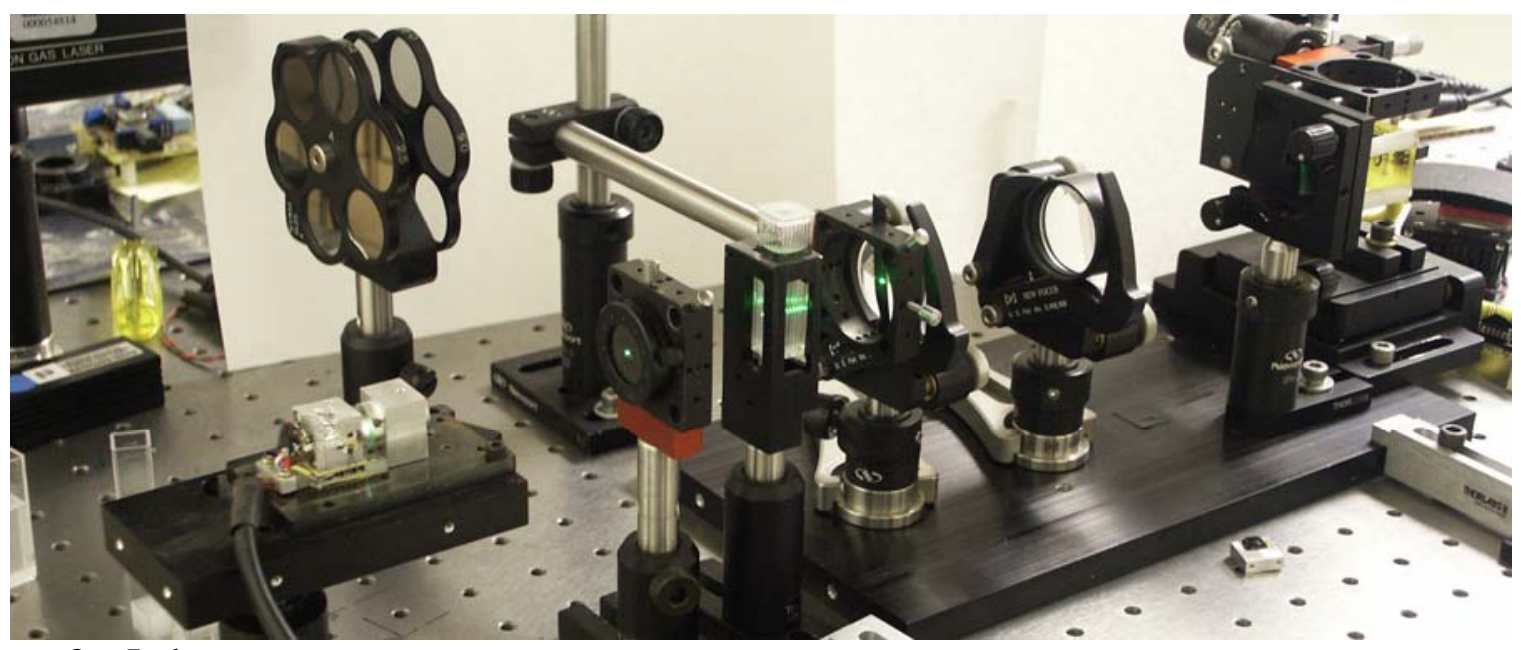

Figure 2a. Laboratory setup

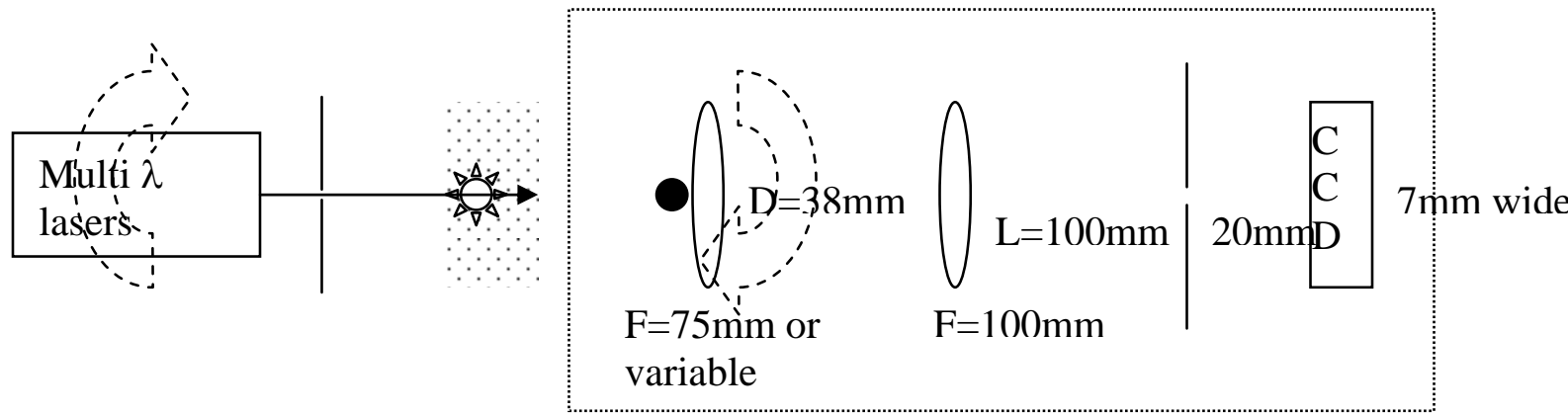

Figure 2b. Schematic of the 2 box setup with the detector box shown with detailed dimension and schematic 


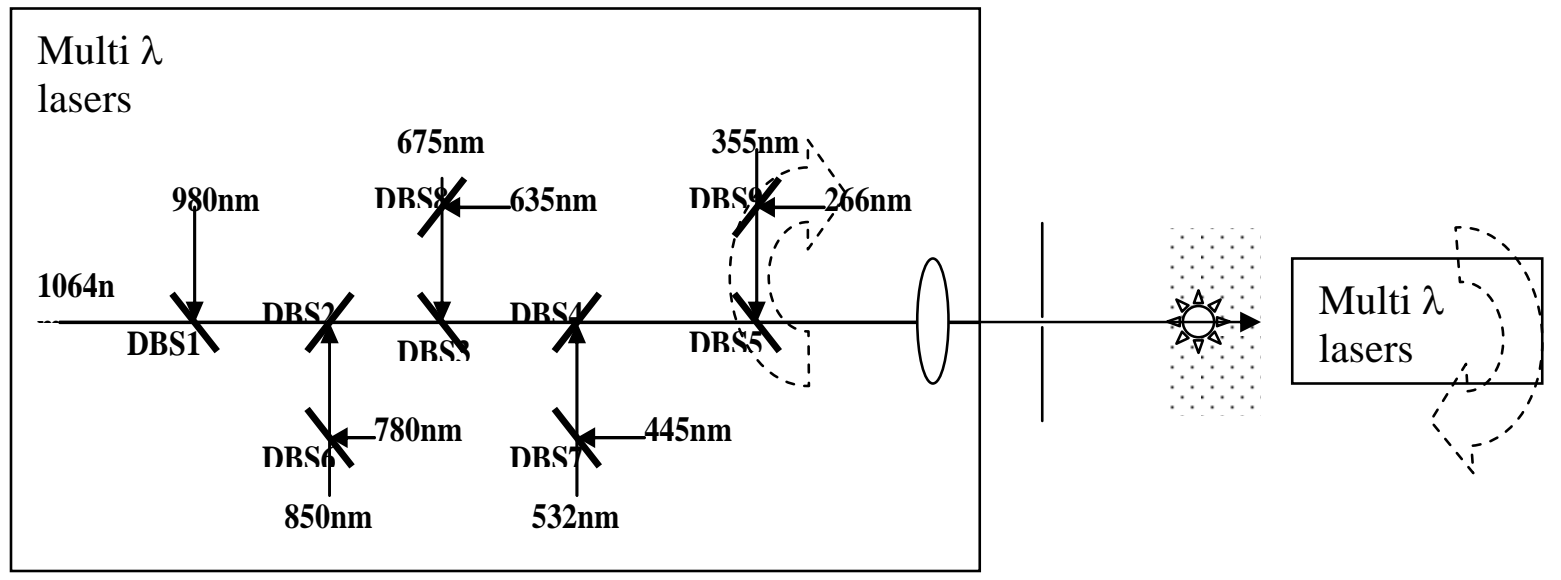

Figure 2c. Schematic of the 2 box setup with the multi-wavelength laser box shown with detailed dimension and schematic

Figure 2d. The boxed pair containing the multiwavelength laser system and the CCD detection system. 


\section{c. Electronics control box}

We build 3 circuits for the operation, control and ADC conversion of the signal for the ELIS1024. We also integrated the LD driver into the boxes, and fitted with rugged cover and power supply that could be powered with unstable power lines, e.g. from power generator, so now all the equipment could be operated in the field.

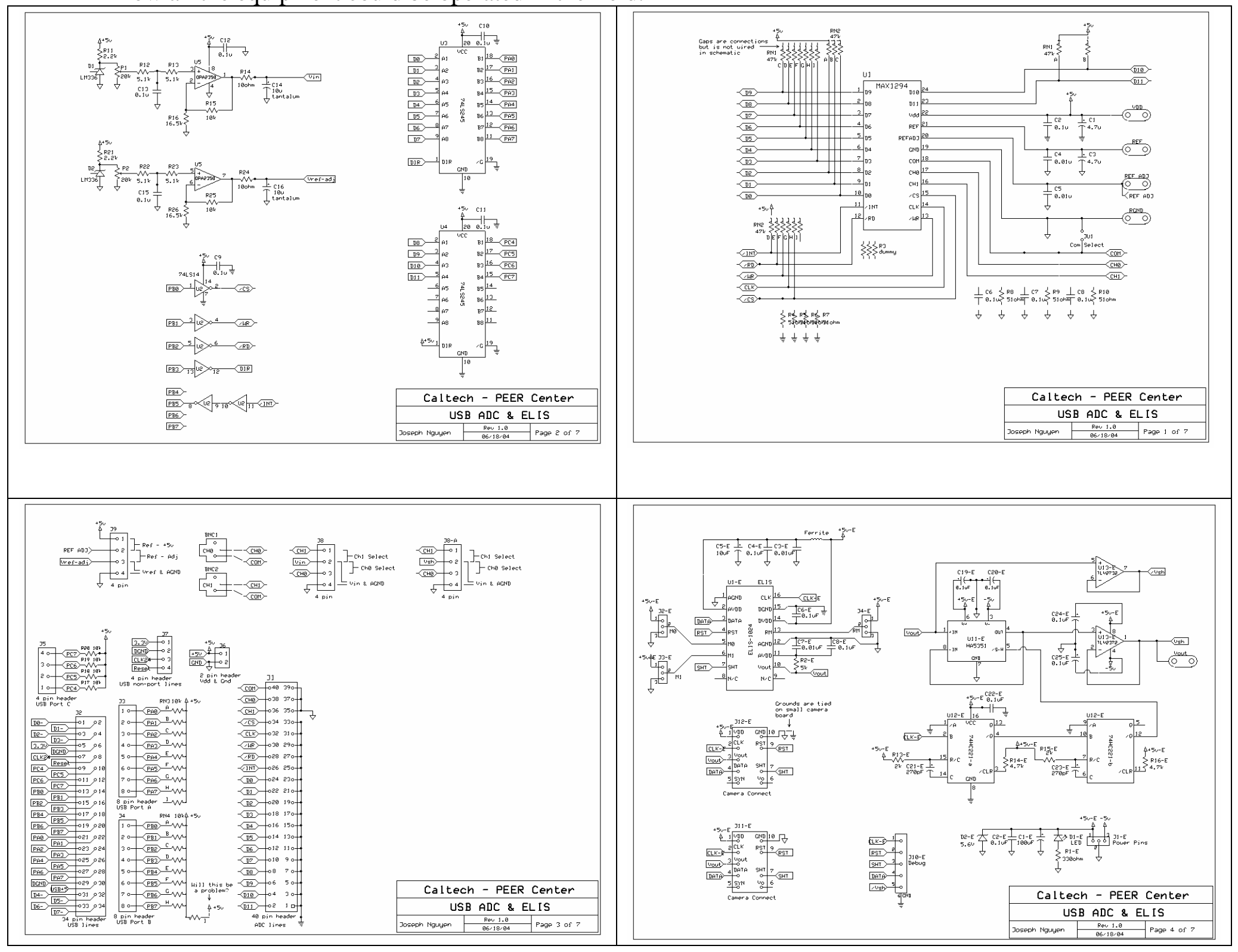




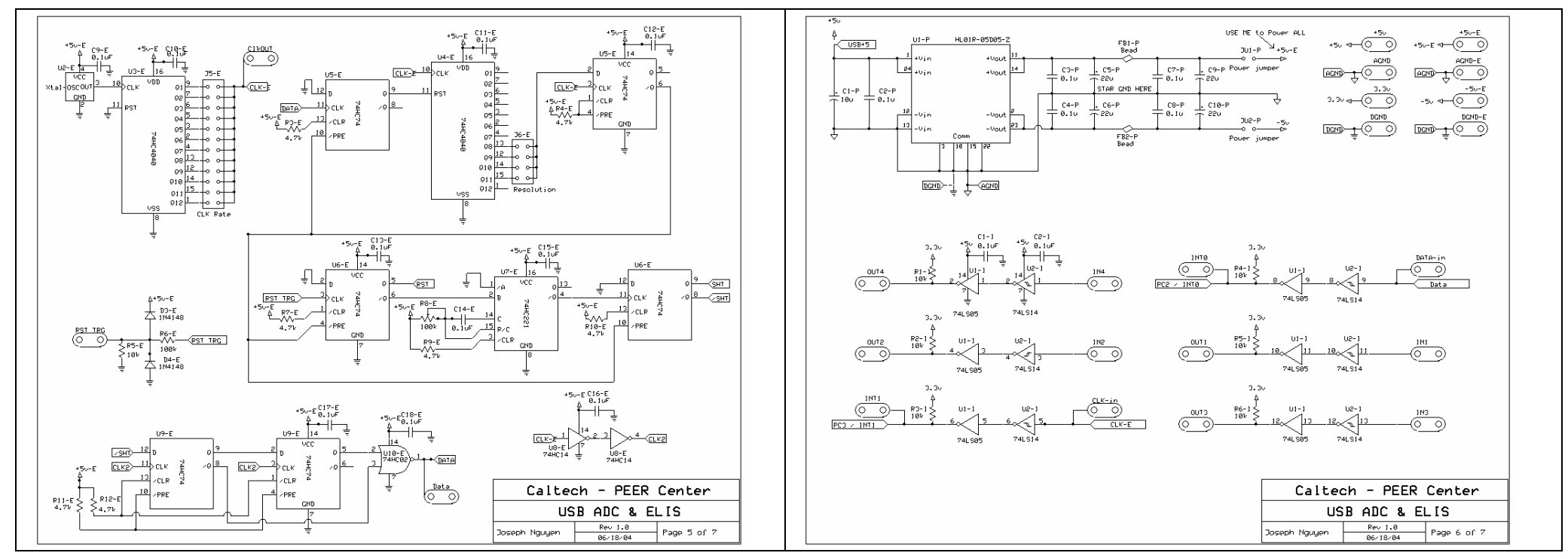

Figure 3. Schematic for the USB ADC card for fast gating and linear CCD (ELIS1024 from Silicon Video, Inc.) data collection

Figure 3 contains the schematic for the USB ADC + ELIS CCD circuit board, and this board is controlled by a USB controller (Cypress EZUSB) which is plug and play on a PC computer.

We have also developed an interface board that allow the same USB controller to control the diode laser array board, with $8 \mathrm{I} / \mathrm{O}$ pins from the USB controller card, we could control the ON/OFF switching of each of the 8 diode lasers with a timing accuracy of $1 \mu$ sec, and pulse width accuracy of $0.5 \mu$ sec with a minimal pulse width of $10 \mu \mathrm{sec}$. In our data collection, we will be firing the diode lasers and the DPSSL laser one at a time, and collect the signal during each shot pulse width. Because the ELIS CCD has the capability of conducting synchronized integration as short as 100ns, we could easily achieve high repetition rate scattering and at the same time reduce the noise level of the ambient light.

\section{Results of light scattering microscopy}

We continued our quest for using laser light scattering under microscopy to image particulates with dimensions under optical resolution. Our ultimate goal is demonstrate the capability in imaging such particulates (size less than 100nm diameter) and be able to track their movement and change in size as they grow, explode/implode, or dissolve. One major application of such technique is to monitor/track the virus pathways in biological cells, because the size of virus is often $100 \mathrm{~nm}$, and the density is much higher than the bulk cell environment.

To demonstrate such capability, we collaborated with Pun group at University of Washington who synthesize virus/DNA stimulant particulates, which could travel into the cells. We hope to see and track such particulates. Shown in figure 5a, is the normal microscopic image of the cell doped with such fine particles. The bright area in the center is the image of the illuminate lamp. We could see the cells with different shapes. 


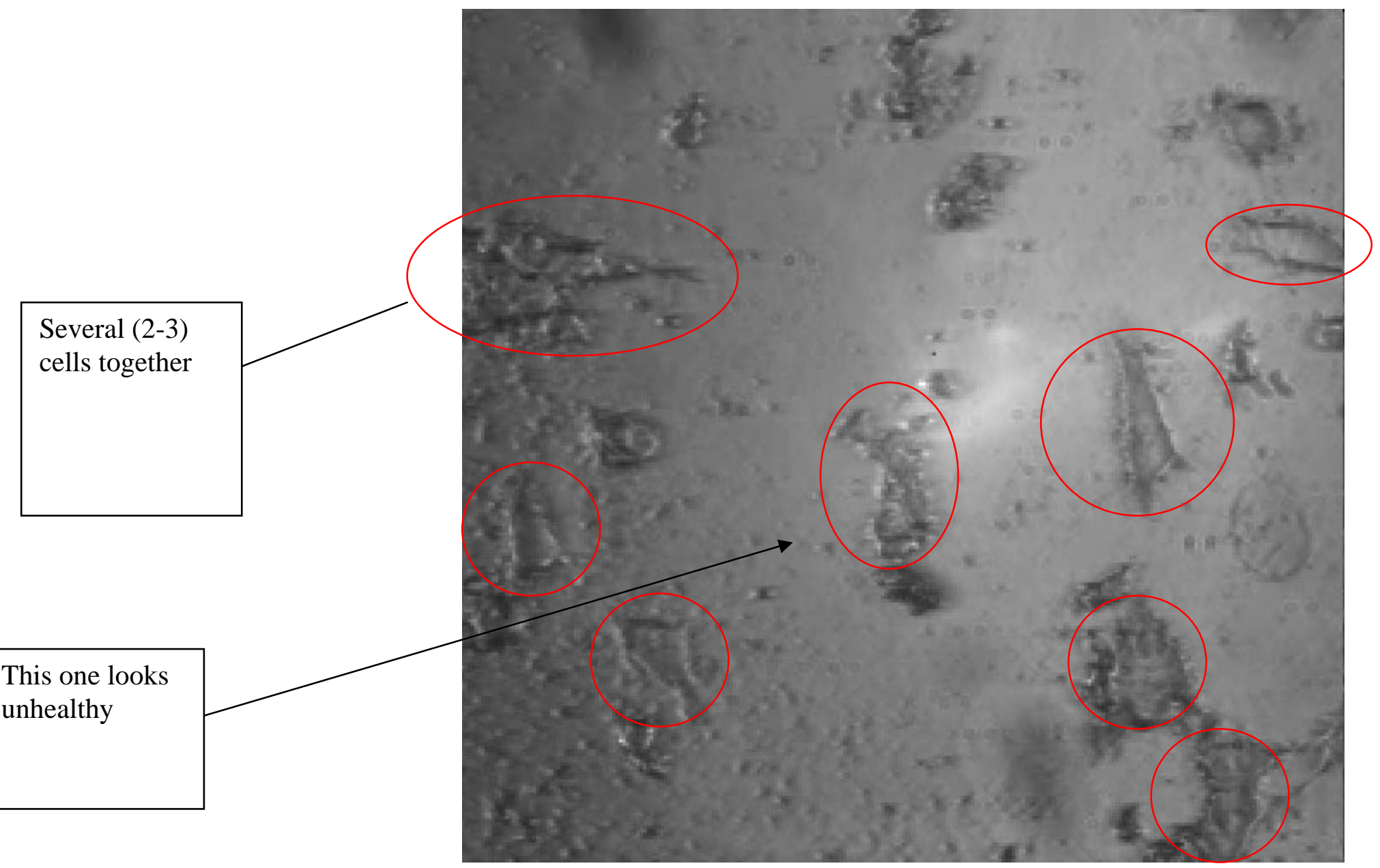

Figure 5a. The width of the image is 160um. The first image (5a) is with regular illumination only, and $2^{\text {nd }}(5 b)$ image is with $532 \mathrm{~nm}$ laser scattering only, the $3^{\text {rd }}$ image (5c) is with both $532 \mathrm{~nm}$ and regular illumination. Cells are in red circles. 

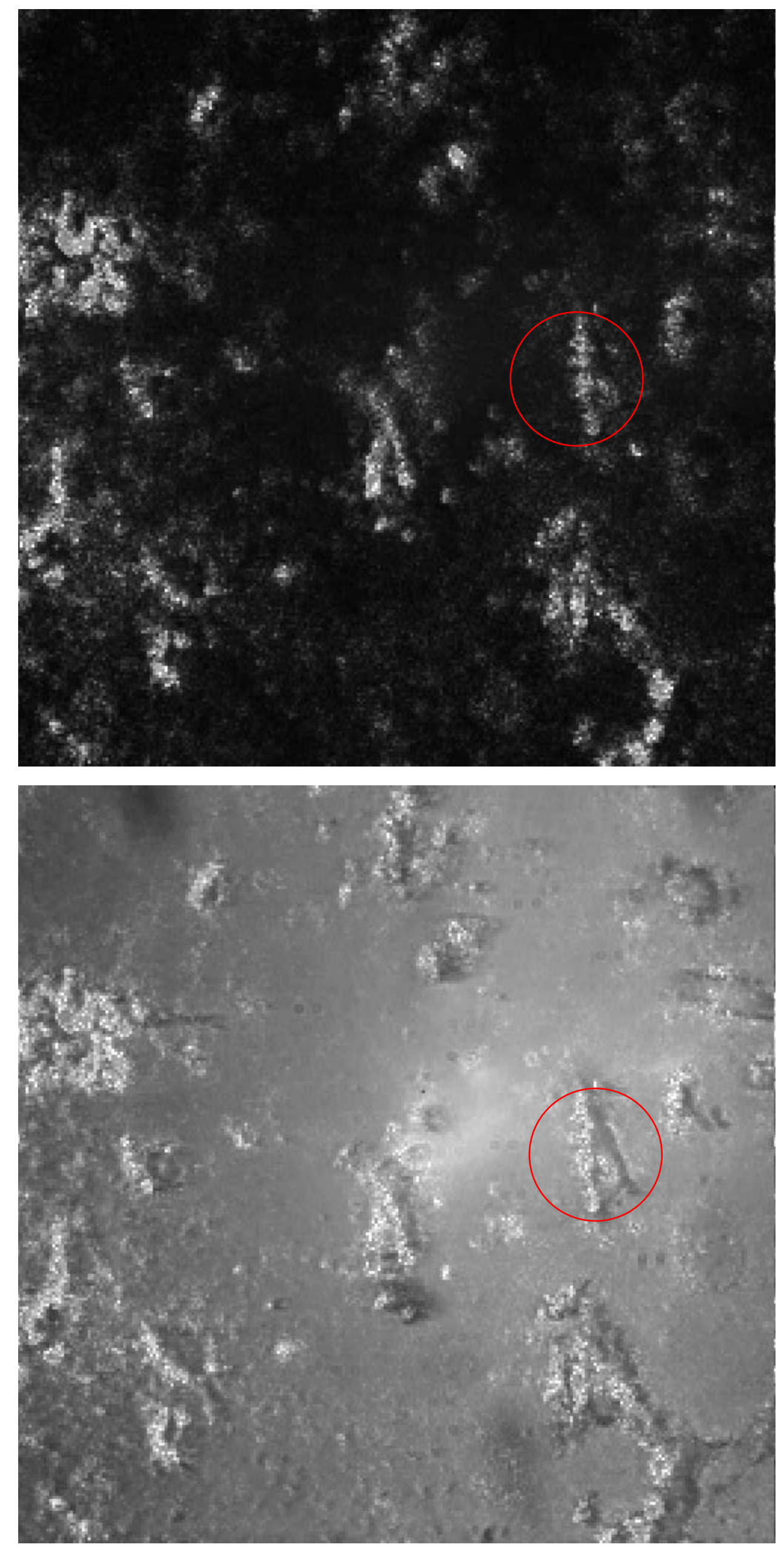
Figure 5b. and 5c. The width of the image is 160um. The Figure on top (5b) image is with $532 \mathrm{~nm}$ laser scattering only, and the figure at the bottom (5c) is with both 532nm and regular illumination.

Figure $5 b$ and $5 c$ are the pictures taken under laser light scattering conditions. Figure $5 \mathrm{~b}$ is under total darkness, i.e. no normal illumination is present; while figure $5 \mathrm{c}$ is taken under weak normal illumination. We could easily see there hundreds of particles in the vicinities and the inside of the cells. The results clearly demonstrate the capability of the microscopic laser scattering technique. We will further our work in this technique, i.e. demonstrate the scattering pattern of each particle (bright spot) and try to monitor the size change; we will also try to track the positions of particles (bright spots) and the information will help our understanding of their parthways inside biological cells.

\section{Computer program that simulates scattering with lasers of different wavelengths}

We retrofit our previous data collection program, which is based on a PCI ADC card (NI 6230E) in a desktop computer, for this new USB ADC + ELIS CCD box. Also, we added program that controls the diode laser array which is also controlled by the USB ADC.

\section{Results and Discussion}

\section{Fast laser switching capability}

We have designed firmware for the USB controller and also the PC host program which controls the firing for the laser diode array. With $8 \mathrm{I} / \mathrm{O}$ pins from the USB controller card, we could control the ON/OFF switching of each of the 8 diode lasers with a timing accuracy of $1 \mu$ sec, and pulse width accuracy of $0.5 \mu$ sec with a minimal pulse width of $10 \mu$ sec.

We are also developing a digital controlled integration timing circuit for the CCD detector, so that we could also control the CCD through the USB controller. Currently, this timing is only adjustable manually through the variable resistor pot.

\section{Microscopy application and single particulate analysis}

Besides the preliminary results presented above for the nanosize particles inside biological cells, we have also applied our laser scattering microscopy to the study of emulsion process. This technique helped greatly in our understanding on the growth of wax particles during the emulsion process. A copy of the paper manuscript ready for submission is included in this report. Currently, we are also pursuing the capability of calculating/estimating the size change from the scattering pattern change, besides just the monitoring brightness of each spot. This capability will help us greatly in our further understanding of the crystallization process during emulsion and other phase change processes. 


\section{Work plan for the 8 the quarter of the project}

We see our work is within our schedule as outlined in the Statement of Work (SOW) at the start of this project.

Currently, we are finishing the following work to prepare for the field test:

- The detection setup in a sealed box to allow the measurement to be conducted in open air.

- The electronics for the data acquisition so that we could control and instrument with notebook computers and therefore use it in the field

We expect that by the end of September, we will have the first unit installed in the field for examining the emission from a turbine/diesel engine. We will also first test our instrument with the water particle generate that Alturdyne build for water particle spray inside combustion engines. 


\section{REFERENCES}

1. C. F. Bohren and D.R. Huffman, Absorption and Scattering of Light by small particles, Wiley-InterScience, 1998, ISBN0-471-29340-7

2. Z. Cheng, P. M. Chaikin, and T. G. Mason, Light Streak Tracking of Optically Trapped Thin Microdisks, PHYSICAL REVIEW LETTERS VOLUME 89, NUMBER 10 108303, 2002

3. Priya S. Niranjan et al. The polymerization of actin: Thermodynamics near the polymerization line, J. Chem. Phys. VOLUME 119, 4070-4084, 2003

4. Robert J. Pelham Jr \& Fred Chang, Actin dynamics in the contractile ring during cytokinesis in fission yeast, NATURE, VOL 419, 82-86, 2002

5. Giovanni Cappello,* Mathilde Badoual, Albrecht Ott, Jacques Prost, Lorenzo Busoni, Kinesin motion in the absence of external forces characterized by interference total internal reflection microscopy, PHYSICAL REVIEW E 68, 021907, 2003

6. A. Meller, R. Bar-Ziv, T. Tlusty, E. Moses, J. Stavans, and S. A. Safran, Localized Dynamic Light Scattering: A New Approach to Dynamic Measurements in Optical Microscopy, Biophysical Journal Volume 74 15411548, March 1998

7. A. Ashkin, J. M. Dziedzic \& T. Yamane, Optical trapping and manipulation of single cells using infrared laser beams Nature 330, 769 - 771 (1987)

8. R. Bar-Ziv, A. Meller,1 T. Tlusty, E. Moses, J. Stavans, and S. A. Safran, Localized Dynamic Light Scattering: Probing Single Particle Dynamics at the Nanoscale PHYSICAL REVI EW LETTERS 154-157, VOL 78, 1997

9. Masayoshi Nishiyama, Etsuko Muto, Yuichi Inoue, Toshio Yanagida and Hideo Higuchi Substeps within the 8$\mathrm{nm}$ step of the ATPase cycle of single kinesin molecules NATURE CELL BIOLOGY 428-431 VOL 32001

10. Braslavsky I, Amit R, Ali BMJ, et al. Objective-type dark-field illumination for scattering from microbeads, APPL OPTICS 40 (31): 5650-5657 NOV 12001

11. Boaz A. Nemet,* Yossef Shabtai, and Mark Cronin-Golomb, Imaging microscopic viscosity with confocal scanning optical tweezers, OPTICS LETTERS / Vol. 27, No. 4 / 264-266, 2002

12. Warren Wiscombe, “'Improved Mie Scattering Algorithms,” Appl. Opt. 19(9), 1505-1509, 1980. Dr. Warren Wiscombe's MIEV0 program, written in FORTRAN 77, is available by anonymous ftp from climate.gsfc.nasa.gov in subdirectory pub/wiscombe/single_scatter/homogen_sphere/exact_mie 


\section{Appendix:}

Planed schedule from the statement of work

\begin{tabular}{|c|c|c|}
\hline Task & Technical Milestone & Schedule \\
\hline \multirow[t]{2}{*}{$\begin{array}{l}\text { 1. Assembly of the multiwavelength } \\
\text { light source }\end{array}$} & $\begin{array}{l}\text { Ready diode \& DP chip lasers, } \\
\text { drivers }\end{array}$ & Month 1-6 \\
\hline & Ready beam combination system & Month 1-6 \\
\hline $\begin{array}{l}\text { 2. Construction of the PM } \\
\text { synthesizer }\end{array}$ & $\begin{array}{l}\text { Verify that monosize PM are } \\
\text { generated }\end{array}$ & Month 1-6 \\
\hline \multirow{2}{*}{$\begin{array}{l}\text { 3. Simulation of Ralyeigh and Mie } \\
\text { Scattering }\end{array}$} & Literature review & Month 1-3 \\
\hline & $\begin{array}{l}\text { reviewComputer program that } \\
\text { could generate simulated } \\
\text { scattering spectrum }\end{array}$ & Month 1-6 \\
\hline \multirow[t]{2}{*}{$\begin{array}{l}\text { 4. Laboratory demonstration of } \\
\text { instrument }\end{array}$} & $\begin{array}{l}\text { Experimental } \\
\text { spectrum database for different } \\
\text { PM sizes }\end{array}$ & \multirow[t]{2}{*}{ Month 7-18 } \\
\hline & $\begin{array}{l}\text { Compare with theory and } \\
\text { conventional PM monitoring } \\
\text { data }\end{array}$ & \\
\hline $\begin{array}{l}\text { 5.Application of the PM analyzer to } \\
\text { a combustion environment: engine } \\
\text { intake area }\end{array}$ & $\begin{array}{l}\text { Correlation of our instrument } \\
\text { data with conventional PM } \\
\text { monitoring data }\end{array}$ & Month 13-24 \\
\hline $\begin{array}{l}\text { 6.Application of the PM analyzer to } \\
\text { a combustion environment: engine } \\
\text { exhaust }\end{array}$ & $\begin{array}{l}\text { Correlation of our instrument } \\
\text { data with total PM mass } \\
\text { emission, new data (PM size and } \\
\text { chemical composition) about in- } \\
\text { situ PM monitoring }\end{array}$ & Month 13-24 \\
\hline $\begin{array}{l}\text { 7. Applicability assessment for PM } \\
\text { emissions from coal fired power } \\
\text { plants }\end{array}$ & $\begin{array}{l}\text { Design/modify our } \quad \text { PM } \\
\text { instrument for smoke stack } \\
\text { monitoring }\end{array}$ & Month 24-30 \\
\hline 8. Instrument design optimization & $\begin{array}{l}\text { Optimize the instrument during } \\
\text { different experiments }\end{array}$ & Month 13-36 \\
\hline
\end{tabular}

